\title{
Mewujudkan Sekolah Peduli Dan Berbudaya Lingkungan Menggunakan Model Make A Match
}

\author{
Agustina Tyas Asri Hardini \\ Program Studi Pendidikan Guru Sekolah Dasar, Fakultas Keguruan dan Ilmu Pendidikan, \\ Universitas Kristen Satya Wacana \\ tyas.asri@staff.uksw.edu
}

\begin{abstract}
ABSTRAK
SD Kanisius Cungkup Salatiga merupakan salah satu sekolah yang potensial untuk dijadikan sekolah Adiwiyata, namun warga sekolahnya belum pernah mendapatkan sosialiasasi terkait sekolah Adiwiyata termasuk peserta didiknya. Untuk itu FKIP-UKSW terpanggil untuk membantu melakukan sosialisasi kepada warga sekolah di SD Kanisius Cungkup Salatiga terkait peran untuk menjaga lingkungan hidup. Sosialisasi yang dilakukan dikemas dalam pembelajaran yang menggunakan model make a match yang disesuaikan dengan karakteristik siswa kelas II SD. Berdasarkan lembar kerja peserta didik sebagai evaluasi kegiatan, sejumlah 22 siswa $(84,6 \%)$ dari 26 siswa telah berhasil membedakan kegiatan yang menjaga lingkungan dan kegiatan yang dapat merusak lingkungan. Siswa mampu memahami tindakan sehari-hari yang dapat dilakukan dalam upaya pelestarian lingkungan hidup. Dengan demikian model make a match yang dilakukan melalui kegiatan pengabdian masyarakat dianggap berhasil meningkatkan pemahaman siswa terkait peran untuk menjaga lingkungan.
\end{abstract}

Kata kunci: Adiwiyata, lingkungan hidup

\section{ABSTRACT}

SD Kanisius Cungkup Salatiga is one of the potential schools to be used as an Adiwiyata school. But the school has never gained socialization related to Adiwiyata school including the students. For that FKIP-UKSW called for help to socialize to the school residents in SD Kanisius Cungkup Salatiga related role to keep the environment. The socialization carried out in the learning that uses a make a match model adapted to the characteristics of grade II students. Based on the student's worksheet as an evaluation of activities, a number of 22 students (84.6\%) of 26 students have succeeded in distinguishing activities that safeguard the environment and activities that can damage the environment. Students are able to understand the daily actions that can be performed in enviromental conservations efforts. Thus, make a match models conducted through community service activities are considered to succeed in increasing students ' understanding of the role to safeguard the environment.

Keywords: Adiwiyata, enviroment

\section{PENDAHULUAN}

Pembangunan pada saat ini mengalami perkembangan di berbagai sektor. Namun sayangnya hal tersebut juga berdampak pada banyaknya bencana lingkungan/permasalahan lingkungan, antara lain: longsor, banjir, kebakaran hutan, yang menimbulkan kerugian baik materi maupun korban manusia. Kerusakan lingkungan hidup sudah mengancam kehidupan manusia, kerusakan makin hari makin bertambah banyak dan beragam. Kerusakan lingkungan hidup seperti pencemaran udara, pencemaran tanah, pencemaran air, peningkatan suhu udara karena pemanasan global semakin nyata terjadi.

Pemerintah dalam hal ini Kementerian Lingkungan Hidup mencanangkan agar dimasukkannya pendidikan lingkungan hidup di sekolah-sekolah.Hal ini dimaksudkan agar institusi pendidikan juga mampu untuk turut serta mengambil peran dalam pengelolaan lingkungan yang lebih baik. Semua elemen masyarakat sadar untuk turut melaksanakan upaya-upaya penyelamatan dan pelestarian lingkungan hidup. Pendidikan Lingkungan Hidup (PLH) diharapkan dapat menjadi salah satu alternatif solusi yang efektif dalam upaya 
meningkatkan pengetahuan dan pemahaman masyarakat terhadap pelestarian fungsi lingkungan hidup. PLH pada jenjang Pendidikan dasar dan menengah perlu terus dikembangkan untuk memberikan pemahaman, penyadaran, dan tuntunan kepada siswa dalam bersikap dan berperilaku peduli dan berbudaya lingkungan. Program diharapkan dapat menjadi salah satu alternatif solusi dalam upaya meningkatkan pengetahuan dan pemahaman masyarakat terhadap pelestrian fungsi lingkungan hidup (Panduan Adiwiyata, 2012).

Menyingkapi hal tersebut, Kementerian Negara Lingkungan Hidup pada tahun 2006 mencanangkan Program Adiwiyata sebagai tindak lanjut dari kerjasama pada tanggal 3 Juni 2005 antara Kementerian Negara Lingkungan Hidup dan Departemen Pendidikan Nasional. Kedua kementerian ini menandatangani kesepakatan bersama nomor: KEP.07/MENLH/06/2005 dan diperbaharui 1 Februari 2010 tentang pembinaan dan pengembangan pendidikan lingkungan hidup. Adiwiyata dapat diartikan sebagai suatu tempat yang baik dan ideal. Suatu tempat untuk mendapatkan dasar berbagai ilmu pengetahuan dan norma serta etika. Sehingga manusia mempunyai dasar untuk mencapai kesejahteraan hidup dan cita-cita pembangunan berkelanjutan.Tujuan program adiwiyata adalah mewujudkan warga sekolah yang bertanggung jawab dalam upaya perlindungan dan pengelolaan lingkungan hidup melalui tata kelola sekolah yang baik untuk mendukung pembangunan berkelanjutan.

Model sekolah Adiwiyata adalah suatu program pendidikan lingkungan hidup yang ditujukan bagi pemberdayaan sekolah di tingkat SD, SMP, dan SMA. Untuk mewujudkan sekolah yang peduli dan berbudaya lingkungan maka diperlukan model pengelolaan sekolah yang mendukung dilaksanakannya pendidikan lingkungan hidup oleh semua warga sekolah sesuai dengan prinsip-prinsip dasar Program Adiwiyata yakni Partisipatif dan Berkelanjutan. Indikator keberhasilan program Adiwiyata ada meliputi 4 faktor, yaitu : 1).Pengembangan Kebijakan Sekolah yang diperlukan untuk mewujudkan Sekolah Peduli dan Berbudaya Lingkungan; 2).Pengembangan Kurikulum Berbasis Lingkungan; 3).Pengembangan Kegiatan Berbasis Parsitipatif; dan 4).Pengelolaan dan atau pengembangan Sarana Pendukung Sekolah. (Panduan Adiwiyata, 2012)
Berdasarkan data yang diperoleh dari Dinas Lingkungan Hidup Salatiga hanya terdapat 27 sekolah (17\%) dari jumlah 156 sekolah yang meliputi SD, SMP dan SMA yang telah dinyatakan menjadi sekolah Adiwiyata, dengan persebaran sebagai berikut: 10 sekolah Adiwiyata jenjang SD, 9 Sekolah Adiwiyata di jenjang SMP, dan 8 Sekolah Adiwiyata di jenjang SMA. Jumlah tersebut sangatla sedikit dibandingkan jumlah sekolah yang ada di Salatiga.

Untuk itulah Fakultas Keguruan dan Ilmu Pendidikan bekerja sama dengan Dinas Lingkungan Hidup Kota Salatiga bermaksud untuk melakukan sosialisasi ke Sekolahsekolah yang ada di area kota Salatiga untuk menanamkan sekolah peduli dan berbudaya lingkungan dalam kegiatan Orientasi Mahasiswa Baru UKSW tahun 2018, supaya masyarakat lebih perduli terhdapa keadaan di sekitar lingkungannya. Salah satu sekolah yang menjadi sasaran kegiatan pengabdian masyarakat ini adalah SD Kanisus Cungkup Salatiga. SD tersebut dipilih karena lokasi sekolahnya yang cukup strategis disertai dengan halaman yang cukup luas sehingga sangat berpotensi untuk dijadikan sekolah Adiwiyata. Selain itu pihak FKIP UKSW juga telah memiliki perjanjian kerjasama dengan pihak SD Kanisius Cungkup Salatiga, sehingga sekolah-sekolah mitra yang dijadikan sasaran utama dalam kegiatan pengabdian masyarakat yang dilakukan FKIP UKSW.

\section{METODE KEGIATAN}

Realisasi pemecahan masalah dengan menggunakan model cooperative learning tipe make a match. Penggunaan model ini dirasa paling tepat untuk mengajarkan peserta didik sikap peduli terhadap lingkungan. Make a Match adalah model pembelajaran yang dikembangkan oleh Lorna Curran (1994) yang menyatakan bahwa model pembelajaran Make a Match mengajak siswa untuk mencari pasangan sambil mempelajari topik tertentu dengan suasana yang menyenangkan. Make a Match bisa diterapkan untuk semua mata pelajaran dan tingkatan kelas. Menurut Kurniasih \& Sani (2013:55) make a match adalah model pembelajaran yang melibatkan siswa untuk mencari pasangan sambil belajar mengenai suatu konsep atau topik dalam suasana yang menyenangkan. Tujuan utama dalam pembelajaran model Make A Match ini adalah untuk melatih siswa lebih cermat, dapat berpikir cepat, ulet, dan memiliki pemahaman yang kuat mengenai materi serta dapat 
berinteraksi sosial dengan temannya (Hosnan,2014).

Sedangkan Rusman (2012:223-224) menyatakan langkah-langkah model pembelajaran Make a Match yaitu sebagai berikut:

1. Guru menyiapkan beberapa kartu yang berisi beberapa konsep/topik yang cocok untuk sesi review (satu sisi kartu berupa kartu soal dan sisi sebaliknya berupa kartu jawaban).

2. Setiap siswa mendapat satu kartu dan memikirkan jawaban atau soal dari kartu yang dipegang.

3. Siswa mencari pasangan yang mempunyai kartu yang cocok dengan kartunya (kartu soal/kartu jawaban).

4. Siswa yang dapat mencocokkan kartunya sebelum batas waktu diberi poin.

Kegiatan perencanaan dilakukan $\mathrm{H}-1$ sebelum pelaksanaan Pengabdian Masyarakat. Pengabdi memberikan pembekalan kepada mahasiswa baru terkait pelaksanaan kegiatan. Pembekalan ini diberikan supaya mahasiswa paham dengan tugasnya masing-masing untuk kegiatan pengabdian. Pengabdi bersama mahasiswa baru yang dilibatkan kegiatan mempersiapkan kartu gambar yang sesuai topik terkait menjaga lingkungan. Berbagai gambar di cari dipotong dan dibuat menjadi kartu gambar untuk nanti dibagikan ke siswa, baik dalam kegiatan kelompok ataupun kegiatan individu. Pengabdi dan mahasiswa baru juga memotong gambar yang nantinya akan digunakan sebagai lembar kerja siswa (LKS). Siswa akan diminta mencocokkan gambar dengan kolom yang sesuai dengan gambar. Beberapa gambar disediakan meliputi kegiatan menjaga lingkungan dan kegiatan yang menyebabkan lingkungan menjadi kotor. Setiap siswa akan dibagikan 20 gambar sebagai LKS, dimana LKS tersebut pengabdi pergunakan sebagai alat untuk mengevaluasi keberhasilan dari kegiatan pengabdian yang dilakukan.

Adapun sasaran dari kegiatan pengabdian masyarakat ini adalah siswa kelas II di SD Kanisius Cungkup Salatiga semester I tahun pelajaran 2018/2019 yang berjumlah 26 siswa dan juga mahasiswa baru (maba) program studi Pendidikan Guru Sekolah Dasar Fakultas Keguruan dan Ilmu Pendidikan Universitas Kristen Satay Wacana Angkatan 2018 yang berjumlah 14 mahasiswa.

\section{HASIL \& PEMBAHASAN}

Pelaksanaan kegiatan pengabdian di masing-masing kelas dikemas dengan cara yang berbeda-beda oleh masing-masing Dosen pengabdi. Adapaun kegiatan yang berlangsung di kelas II SD Kanisius Cungkup Salatiga sebagai berikut:

\section{Kegiatan awal pembelajaran}

Kegiatan diawali dengan melakukan perkenalan kepada siswa. Pengabdi memperkenalkan diri bersama mahasiswa baru Angkatan 2018. Kemudian dilakukan pengecekan kehadiran siswa, dan dilanjutkan dengan mempersiapkan siswa untuk mengikuti kegiatan. Pengabdi menyebutkan judul dari pengabdian yang dilakukan dan memberitahuan tujuan dari pelaksanaan kegiatan pengabdian masyarakat. Pengabdi memberikan beberapa aturan di dalam kelas, contohnya siswa harus mengangkat tangan terlebih dahulu dan baru menjawab setelah dipersilahkan, ketika pengabdi mengangkat 2 jari, tandanya siswa harus duduk dengan tenang dan tidak bersuara.

Pengabdi kemudian melakukan tanya jawab dengan siswa terkait lingkungan hidup misalnya: "Apakah kalian merasa udara sangat panas di ruangan ini? Ataukah kalian merasa ruang kelas kita sangat sejuk?" Setelah siswa menjawab, pegabdi kemudian mengajak siswa untuk menuju ke pohon besar yang ada di depan kelas mereka dan kembali bertanya kepada siswa "Sekarang bagaimana rasanya ketika kalian berada di bawah pohon? Apakah kalian merasakan panas atau merasa sejuk?" setelah peserta didik menjawab, pengabdi bersama siswa kembali ke ruang kelas.Pengabdi kembali melakukan tanya jawab dengan siswa sampai siswa memperoleh kesimpulan bahwa area yang dipenuhi dengan tanaman dan pepohonan akan lebih sejuk dan nyaman.

\section{Kegiatan Inti Pembelajaran}

Pengabdi kemudian memberikan contoh pelaksanaan model make a match secara klasikal di dalam kelas. Pengabdi menunjukkan gambar sampah berupa kemasan makanan ringan. Siswa diminta untuk menemukan pasangan dari gambar sampah tersebut dengan memilih gambar yang tersedia, untuk selanjutnya gambar dapat ditempel di papan tulis. Siswa yang lainnya diharapkan untuk dapat memeriksa jawaban temannya. Kegiatan ini dilakukan beberapa kali sampai siswa dirasa paham.

Pengabdi kemudian membagi siswa menjadi 4 kelompok besar. Setiap kelompok 
besar tersebut dibagi lagi menjadi 2 kelompok kecil dengan pembagian sama rata. Dengan bantuan mahasiswa baru, pengabdi membagikan kartu soal dan jawaban yang sudah dipersiapkan sebelumnya ke masingmasing kelompok. Setiap siswa masing-masing mendapatkan 1 kartu. Siswa diberi kesempatan untuk membaca kartu yang dimiliki terlebih dahulu. Pengabdi kemudian menginstruksikan siswa untuk menemukan pasangan dari kartunya di dalam tim yang sudah terbagi secara bersama-sama setelah aba-aba diberikan.

Mahasiswa bertugas mengecek jawaban dari siswa, dan meminta siswa kembali mencari pasangan dari kartunya jika jawaban yang diberikan keliru. Kelompok yang paling cepat menemukan pasangan dari setiap kartu yang dimiliki akan diberi reward berupa poin. Poin yang diperoleh setiap kelompok akan dicatat di papan tulis. Kegiatan ini dilakukan kembali dengan kartu soal dan jawaban yang berbeda-beda. Setelah seluruh kartu soal dan jawaban sudah cocok, kegiatan diakhiri dengan pengumuman kelompok dengan poin tertinggi.Bagi kelompok dnegan poin tertinggi, pengabdi memberikan hadiah alat tulis, sedangkan untuk tim yang lainnya pengabdi memberikan hadiah berupa stiker.

Pengabdi mempertegas dan menjelaskan kembali bentuk perbuatan untuk menjaga lingkungan hidup di sekitar rumah dan sekolah, yang meliputi membuang sampah pada tempatnya, menggunakan air dan listrik sesuai kebutuhan, tidak memetik tanaman dengan sembarangan, ikut perduli terhadap tanaman yang ada di sekitar dengan ikut menyiraminya dan merawat, membuat karya dari barang-barang daur ulang, misalnya membuat tempat pensil dari bekas kemasan makanan ringan, dan lain sebagainya.

Pengabdi kemudian membagikan lembar kerja siswa, dimana siswa diminta untuk mewarnai, memotong, dan menempelkan gambar dengan pasangan kata yang sesuai secara individu.Siswa didampingi oleh mahasiswa baru dalam kegiatan ini.Setiap siswa yang sudah selesai, hasilnya akan diperiksa oleh mahasiswa, untuk kemudian diberikan nilai.

\section{Kegiatan akhir pembelajaran}

Pengabdi bersama dengan siswa menyimpulkan kembali materi tentang lingkungan hidup yang sudah dipelajari bersama. Pengabdi kemudian mengajak siswa untuk menyanyikan lagu "Jangan Membuang Sampah" karya A.T. Mahmud, dilanjutkan dengan mengajak siswa untuk melakukan gerakan SEMUT (Satu Menit Pungut Sampah) di dalam kelas. Kegiatan kemudian diakhiri dengan siswa berdoa bersama.

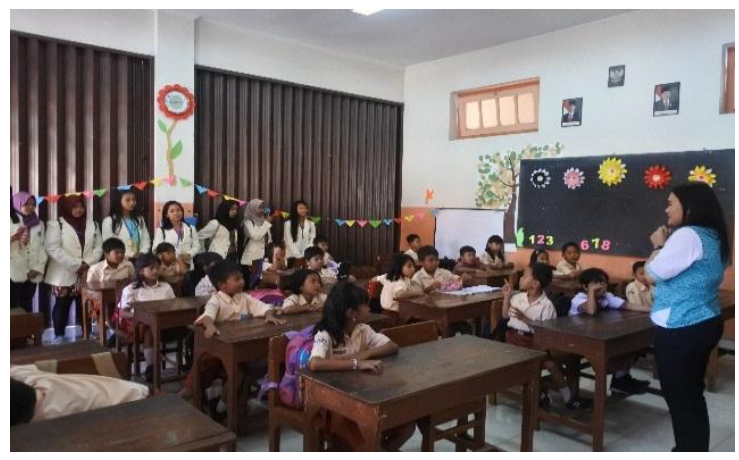

Gambar 1. Perkenalan dan pemberitahuan aturan kelas.

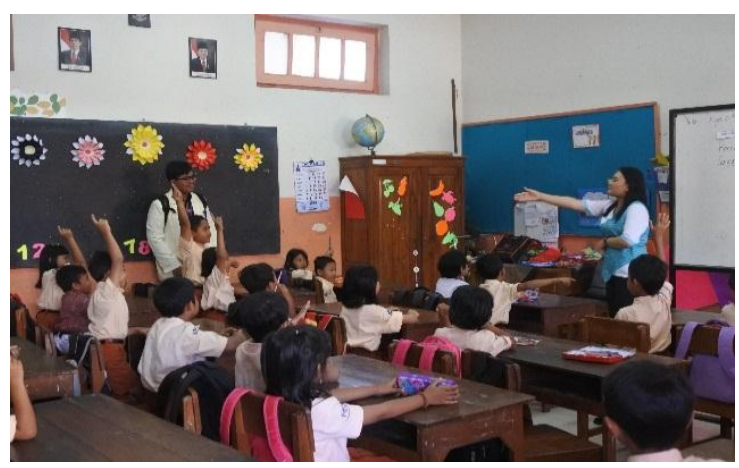

Gambar 2. Kegiatan tanya jawab di kelas

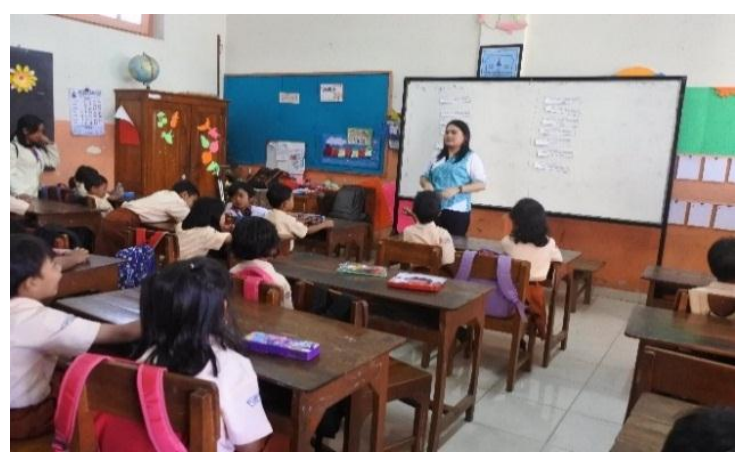

Gambar 3. Pemberian contoh make a match secara klasikal

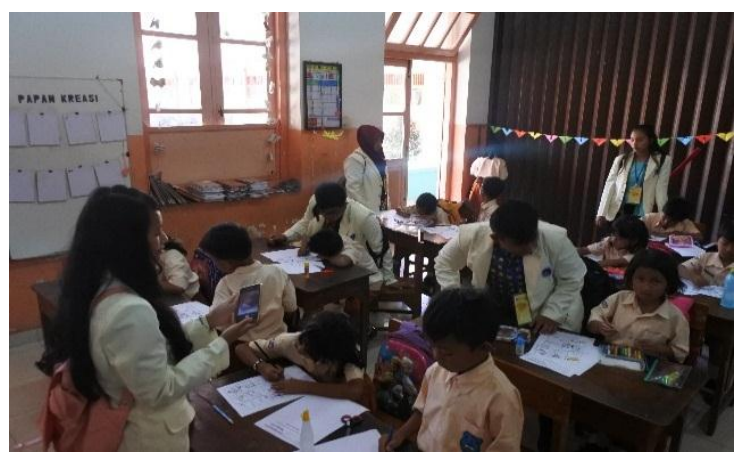

Gambar 4. Pengerjaan LKS dengan pendampingan dari mahasiswa baru

\section{Dampak Kegiatan}


Dari seluruh kegiatan yang dilakukan siswa menjadi tahu pentingnya menjaga lingkungan di sekitarnya melalui tindakantindakan sederhana yang bisa dilakukan setiap hari. Berdasarkan lembar kerja peserta didik yang diberikan sejumlah 22 siswa $(84,6 \%)$ berhasil memasangkan gambar dengan sempurna, yang berarti siswa sudah memahami kegiatan-kegiatan yang harus dilakukan untuk menjaga lingkungan. Model make a match yang digunakan memudahkan siswa untuk memahami materi tentang sekolah adiwiyata yang ingin disampaikan. Hal ini sejalan dengan penelitian yang dilakukan oleh Aziz (2018), Kadarusman, dkk (2018), Yuliana dan Yari (2019), dimana model make a match terbukti berhasil meningkatkan pemahaman peserta didik dalam pembelajaran.

\section{KESIMPULAN \& SARAN}

\section{Kesimpulan}

Pengabdian ini merupakan salah satu upaya yang dilakukan oleh FKIP UKSW bekerja sama dengan Dinas Lingkungan Hidup untuk mensosialisasikan pentingnya menjaga lingkungan demi masa depan bersama. Dari kegiatan yang dilakukan penanaman sikap untuk menjaga lingkungan bisa dilakukan semenjak dini, menggunakan model yang sesuai dengan perkembangan siswa. Pemberian contoh-contoh yang sesuai dengan kehidupan sehari-hari siswa membuat siswa lebih mudah untuk memahami materi yang disampaikan.

\section{Saran}

Untuk mewujudkan sekolah yang peduli terhadap lingkungan perlu dimulai dari warga sekolahnya terlebih dahulu. Semua pihak yang ada di sekolah harus dibiasakan untuk perduli terhadap lingkungan dengan tindakan sederhana yang dilakukan. Orangtua dan keluarga serta pemerintah diharapkan ikut berperan dalam upaya membiasakan anak untuk perduli terhadap lingkungan. Melalui kegiatan ini kami juga berharap dapat menginspirasi pihak sekolah untuk memiliki program-program lain terkait lingkungan hidup dan menjadikan SD Kanisius Cungkup menjadi sekolah Adiwiyata.

\section{DAFTAR PUSTAKA}

Aziz, H. A. 2018. Meningkatkan Hasil Belajar Siswa Melalui Penerapan Model Pembelajaran Cooperative Learning Dengan Metode Make A Match Pada Mata Pelajaran Pendidikan Agama Islam Materi Surah Al-Qodr dan Al-'Alaq Ayat 1-5 Di Kelas VI Sekolah Dasar Negeri 2
Awang Besar Kecamatan Barabai Kabupaten Hulu Sungai Tengah. Jurnal Penelitian Tindakan dan Pendidikan, 4(1).

Curran, Lorna. 1994. Metode Pembelajaran Make a Match. Jakarta: Pustaka Belajar.

Hosnan. 2014. Pendekatan Saintifik dan Kontekstual dalam Pembelajaran Abad 21. Bogor: Ghalia Indonesia.

Kadarusman, G., \& Cahyono, B. E. H. 2018. Penggunaan Media Pembelajaran Pohon Ajaib dengan Model Pembelajaran Make A Match untuk Meningkatkan Penguasaan Kosa Kata Bahasa Indonesia Siswa Tunarungu Kelas II SDLB Dharma Wanita Jiwan Kabupaten Madiun. Linguista: Jurnal Ilmiah Bahasa, Sastra, dan Pembelajarannya, 2(1), 6171.

Kurniasih, Imas dan Berlin Sani. 2015. Ragam Pengembangan Model Pembelajaran untuk Peningkatan Profesionalitas Guru. Yogjakarta: Kata Pena.

Rusman. 2012. Model-model Pembelajaran: Mengembangkan Profesionalisme Guru, RajaGrafindo Persada, Jakarta.

Tim Adiwiyata Nasional. 2012. Buku Panduan Adiwiyata Sekolah Peduli dan Berbudaya Lingkungan. Jakarta: Kementrian Lingkungan Hidup dan Kementrian Pendidikan dan Kebudayaan.

Yuliana, Erfina dan Yari Dwikurnaningsih. 2019. Penerapan Model Make a Match Berbasis Saintifik untuk Meningkatkan Hasil Belajar Tematik Siswa. Publikasi Pendidikan: Jurnal Pemikiran, Penelitian dan Pengabdian Masyarakat Bidang Pendidikan, 9(2). 